\title{
O FINANCIAMENTO \\ DA MANUTENÇÃO E OPERAÇÃO \\ DO SISTEMA DE DRENAGEM \\ URBANA DE ÁGUAS PLUVIAIS \\ NO BRASIL:
}

TAXA DE DRENAGEM

\author{
Cristina Lengler \\ Carlos André Bulhốes Mendes
}

\begin{abstract}
RESUMO Evitar as inundaçóes nas cidades exige um fluxo de receitas para financiar o sistema de drenagem pluvial urbano. Discute-se a recuperação parcial dos recursos públicos gastos na operação e manutenção do sistema local, através da criação da taxa de drenagem, à luz das peculiaridades do sistema tributário brasileiro. Os resultados demonstram que não se trata de um tributo ambiental, pois seu pequeno montante não alteraria conduta poluidora do possuidor do lote. Mas, satisfaz os requisitos de disponibilidade, especificidade e divisibilidade exigidos pelos artigos 77 e 79 do CTN. O critério utilizado para obter o percentual de impermeabilização da zona de estudo combina a classificação de tipos de solo (permeávellimpermeável) e seus usos (públicol privado). Para as zonas maiores utilizou-se a classificaçâo de imagens espectrais, enquanto para quantificar o percentual de área a ser mantida em estado natural nos lotes, se utilizou o estabelecido pelo PDDUA como limite mínimo.
\end{abstract}

P A L A V R A S - C H A V E Extrafiscalidade; Tributação municipal; Tributos imobiliários; Drenagem pluvial urbana.

\section{INTRODUÇÃO}

A quantidade de recursos necessários para financiar os custos de manutenção da qualidade do sistema de drenagem urbana nos municípios brasileiros depende hoje da divisão de recursos entre as demais despesas orçamentárias. A prescrição de percentuais mínimos vinculados com gastos essenciais em Saúde e Educação deixa em plano secundário os gastos com serviços de manutenção e operação de sistemas orgânicos vitais ${ }^{1}$ para o funcionamento das cidades.

Trágicas imagens de deslizamentos e inundaçóes expóem o problema da carência de saneamento básico nas cidades. A falta de recursos financeiros para uma melhor prestaçáo do serviço de drenagem, que contemple desde o planejamento até a execução dos serviços, passando pela gestáo dos recursos humanos, tecnológicos e de capital, parece estar no cerne da problemática.

1 Conforme descrito pelo urbanista francês Donat-Afred Agache (1875-1959). 


\section{EMBASAMENTO LEGAL}

$\mathrm{Na}$ atualidade, as questóes sobre o meio ambiente e o planeta vêm sendo evidenciadas. As mudanças no sistema tributário com visão para o enfoque ambiental vêm acontecendo, principalmente nas naçôes mais desenvolvidas. Tem-se como exemplo o sistema tributário espanhol, que autoriza a instituição de taxas em razáo de utilização de recursos ambientais.

Para a criação de um tributo ambiental, por lei, é necessário, de acordo com Torres (2005, p.104), demonstrar o vínculo entre o "motivo constitucional" (finalidade de preservação e conservação do meio ambiente) e o exercício da competência tributária. Por tratar-se de questão sujeita a tratamento constitucional, o autor recomenda cautela na transposição de entendimentos doutrinários concertados à luz de textos estrangeiros, embora relevantes, pois

[...] nenhum destes pensadores sob a égide de uma Constituiçáo que, em matéria tributária, tenha sido tão analítica quanto a nossa, com prévia identificação das espécies de tributos e respectivas materialidades determinantes do exercício de competência e que se vê, ainda, sujeita à observância de normas gerais sobre legislação tributária e uma série de princípios, imunidades e regras objetivas, tudo no plano constitucional. Esse é um paradigma difícil de alcançar e certamente um óbice ao aproveitamento da experiência externa, o que nos impóe uma construçấo sobremodo original no trato dessas questóes (Torres, 2005, p.97).

Portanto, para o autor, o Estado e a sociedade devem encontrar instrumentos que permitam medidas de conservação ambiental. E, neste sentido, a tributação pode ser uma alternativa. Logo, o desafio imposto está em investigar o espaço para a açáo fiscal no âmbito da competência ambiental e tributária.

No Brasil, a drenagem urbana vem sendo financiada pela receita genérica de impostos. Os impostos são uma obrigação pecuniária do cidadão perante o Estado, independentemente de prestação de uma atividade ou de um serviço específico, devendo ser de natureza geral e indivisível e não ter caráter de puniçẫo. Tem-se, portanto, uma impossibilidade constitucional de vincular a destinação da receita. Assim, é equivocado imaginar que a receita de um imposto deva prover individualmente este ou aquele serviço. Isso acontece porque o objetivo arrecadatório se sobrepóe a qualquer outro, uma vez que se destina a suprir as despesas genéricas do Estado.

Desta feita, na tentativa de ter uma receita específica para o sistema de drenagem urbana, deve-se buscar outra forma de tributação. A instituição de uma taxa de drenagem é frequentemente abordada no meio acadêmico como uma solução para melhorar os serviços de limpeza de bocas de lobo, galerias, dessassoreamento de córregos, manutenção dos reservatórios de retenção, redes de ligaçáo e vistorias em nossas cidades.

Entretanto, diferentemente do imposto, a taxa tem seu fato gerador relacionado com uma atividade estatal específica, decorre do poder de polícia ou da utilização efetiva ou potencial de um bem ou serviço oferecido pelo Estado, de forma divisível e específica. É um tributo contraprestacional e pode, também, ser usado em caráter extrafiscal.

Além disso, o serviço público cobrado por meio de taxa deve atender aos requisitos da disponibilidade, da especificidade e da divisibilidade, previstos nos art. 77 e 79 do Código Tributário Nacional. E ainda, as taxas não podem ter base de cálculo idêntica à de qualquer 
imposto (Súmula no 597 do STF; $\$ 22^{\circ}$ do art. 145 da CF). Assim, o desafio está em se ater ao valor do serviço, dimensionando-o em função de elementos pertinentes à quantificação da utilizaçáo uti singuli² do serviço posto à disposição do sujeito passivo do tributo.

Há um grande debate jurídico sobre a constitucionalidade ou não da cobrança de uma taxa de drenagem. Na mesma linha que ensejou a fulminação, pelo Tribunal de Justiça de Sáo Paulo³, da taxa de drenagem urbana instituída pela Lei no 7.606, de 23 de dezembro de 1997, na cidade de Santo André, SP, Amaral (2007, p.174) entende que, em razão do que determina o inc. II do art. 145 da Constituição brasileira, que prescreve "como fato gerador das taxas apenas o exercício do poder de polícia ou a utilizaçáo efetiva ou potencial de serviços públicos específicos de divisíveis", a tributação de um recurso ambiental de domínio público exclui os bens públicos como fato jurídico tributário de taxa.

De opiniāo diversa, Baptista e Nascimento (2002, p.46) entendem que a taxa de drenagem urbana encontra embasamento legal na Lei $n^{\circ}$ 9.433, de 8 de janeiro de 1997, que institui a Política Nacional de Recursos Hídricos, cria o Sistema Nacional de Gerenciamento de Recursos Hídricos, regulamenta o inc. XIX do art. 21 da Constituiçáo Federal e altera o art. 1ํ da Lei no 8.001, de 13 de março de 1990, que modificou a Lei no 7.990, de 28 de dezembro de 1989, que elenca em seu art. 5o, entre os instrumentos da Política Nacional de Recursos Hídricos, a cobrança pelo uso de recursos hídricos. Entendem os autores que seus artigos 12 e 20 respaldam a adoção da taxa, uma vez que se considere a sujeição à outorga das águas pluviais.

\section{A COBRANÇA PELO RECURSO AMBIENTAL}

Para corrigir as falhas de mercado geradas pela degradação ambiental através da externalidade, e para acabar com quaisquer direitos adquiridos em matéria de poluiçáo, tem-se o princípio poluidor-pagador. No Brasil ainda se discute se ele está incorporado na Constituição Federal, pois não se encontra expresso. Amaral (2007, p.28) informa que em discussóes sobre a Reforma Tributária (PEC 41/2003) foi organizada uma Frente Parlamentar Pró-Reforma Tributária Ecológica, e entre as inserções propostas estava a do princípio poluidor-pagador no Sistema Tributário Nacional. No entanto, logrou-se apenas a ampliação do princípio da defesa do meio ambiente no capítulo da ordem econômica e financeira ${ }^{4}$.

Todavia, Fiorillo e Ferreira (2010, p.187) entendem por desnecessária uma alteração legislativa constitucional. Justificam que o conceito de poluidor-pagador com matriz no art. $225, \$ 3^{\circ}$, da Constituição, reforçado pelo art. 170, inc. VI, alterado pela Emenda Constitucional no 42/2003, veio por superar o conceito de tributo forjado pelo art. 3o do CTN de 1966.

Sebastiāo (2010, p.218) considera que, pelos fundamentos que dela se extrai, a Constituição já teria feito a opção pelo princípio do poluidor-pagador. A autora aponta as duas opçóes possíveis quanto aos encargos relativos à precaução, prevenção e reparaçáo do dano ambiental: a) um Estado de bem-estar ambiental que absorve todos os encargos, desonerando os setores produtivos (mesmo os poluidores) em razão do potencial crescimento econômico advindo da desoneração; b) a adoção do princípio poluidor-pagador, no qual o próprio poluidor é o responsável pelos encargos decorrentes de sua atividade poluente, e não a sociedade como um todo.
2 De forma singular, separada, única.

3 Arguição de Inconstitucionalidade no 990.10.2477401-SP. Em curso, a reclamação no 13.200 , de 25 de janeiro de 2012, junto ao Supremo Tribunal Federal.

4 Determinado pela EC 42/2003 e introduzido no inc. VI do art. 170 da CF/88, passa a considerar a diferenciação do impacto ambiental dos produtos e serviços em seus processos de elaboração e prestação. 
5 EZCURRA, Marta Villar. La fiscalidad al servicio de la eliminación de los residuos urbanos. Noticias da la União Europea, Madrid: Ciss Práxis, v.17, n.193, p.99-124, fev. 2001.

6 BAUMOL, William J.; OATES, Wallace E. The use of standarts and prices for protection of the environment. In: BOHM, Peter; KNEESE, Allen V. (ed.). The economics of environment: papers from Four Nations. London: Macmillan, 1971. p.53-65.

7 Presume-se que o homem moderno tenha um comportamento egoísta, maximizador da sua utilidade individual, pressuposto na análise do mercado, com um comportamento de atuação desinteressada, maximizador do bem-estar coletivo, pressuposto na análise política (BUCHANAN, 1971 apud LAGEMANN, 2002, p.307).

8 "[...] be equal at the margin to his evaluation of the marginal unit of quality he receives." MACAULAY, Hugh. Environmental quality, the market, and public finance. In: BIRD, Richard M.; HEAD, John G. (eds.). Modern fiscal issues: essays in honor of Carl S. Shoup. Toronto: University of Toronto, 1972. p.187-224.
Ezcurra $^{5}$ (apud Amaral, 2007, p.121) constata que a gravidade do problema ambiental atual demonstra certo grau de ineficácia dos instrumentos jurídicos tradicionais para a preservaçáo do meio, assim como a necessidade de financiar projetos ambientais no marco das Fazendas Públicas deficitárias. Logo, ao lado da responsabilidade criminal, civil e administrativa pelos danos ambientais, a tributação ambiental tem o papel de incorporar o custo da poluição ambiental ao uso dos recursos ambientais, internalizando a externalidade negativa ambiental.

O uso de políticas públicas é justificável quando a livre negociação entre as partes não garante o nível eficiente de degradação ambiental. Estabelecer o ponto de equilíbrio entre a preservação da natureza e o desenvolvimento é um processo de profunda reflexão social.

A sugestáo econômica trazida por Lagemann (2002, p.305) para a tributaçáo ecológica é embasada na teoria "padrão de qualidade do meio ambiente-preço" de Baumol e Oates (1971) ${ }^{6}$. Para tanto, "deve ser escolhido um padrão aceitável de qualidade do meio ambiente pelos responsáveis num processo coletivo de decisão, com base nos conhecimentos técnicos das interdependências ecológicas".

\section{DE QUEM COBRAR}

Uma das dificuldades na precificação de um bem público é sua característica de que pode ser desfrutado por uma pessoa sem reduzir o consumo de outras. Entende-se que, devido ao fato de os bens públicos não serem supridos pelo mercado, o Estado deve intervir.

Para Mansfield (1978, p.464), "enquanto a eficiência econômica requer para um bem privado que o benefício marginal de cada consumidor seja igual ao custo marginal, para um bem público ela requer que a soma dos benefícios marginais de todos os consumidores seja igual ao custo marginal". Logo, um dos problemas é fazer com que as pessoas revelem suas verdadeiras preferências ${ }^{7}$, pois elas podem evitar o pagamento e, mesmo assim, obter os benefícios do bem público. Outro é o problema da equidade, ou seja, na definição de qual o nível de redução a ser atingido, o que muitas vezes tende a ser resolvido através de um processo político.

Para alcançar a utilizaçáo racional da natureza e, em especial, a drenagem pluvial urbana, alguns autores defendem que a tributaçáo recaia sobre todos os envolvidos na questão (poluidores e não-poluidores). Então, na presença de uma externalidade negativa (inundação urbana decorrente do aumento da vazão das águas originado pela impermeabilização do solo urbano), ao poluidor cabe a aplicaçáo de um tributo no montante do custo externo marginal causado pelos poluidores. E, para cada não-poluidor, que necessita do serviço de drenagem para manter o uso do espaço urbano habitado ou mesmo para circular na regiáo afetada pelo serviço (consumidores), o valor do tributo "deve ser igual, na margem, a sua avaliação da unidade marginal de qualidade que ele recebe". Entretanto, reconhece-se que a implementação da tributação sobre o não-poluidor está praticamente afastada, pois no campo político é difícil convencê-los a contribuírem para a melhora do meio ambiente por cuja degradaçáo não são os responsáveis (Macaulay ${ }^{8}$, 1972, p.217-218 apud Lagemann, 2002, p.307-309).

\section{COMO COBRAR}

Um dos mecanismos de que o governo dispóe é o uso da taxa de drenagem para regular a poluição promovida pelo aumento da vazáo de água escoada no lote, que advém da 
impermeabilizaçáo do solo. Sob o enfoque fiscal, tudo o que o governo teria de fazer é medir a quantidade de poluição gerada (o excesso de água vertida pelo lote) e taxá-la de acordo.

Cançado e colaboradores (2005, p.19) elencam formas de precificação para a cobrança de taxa de drenagem urbana, seguindo objetivos de eficiência econômica ou de sustentabilidade financeira. Neste sentido, salientam que algumas utilizam o custo marginal ${ }^{9}$ como critério de cobrança, porém em uma base mais ampla, com a incorporaçấo de custos sociais, um horizonte temporal maior ou a viabilidade financeira do empreendimento, e outras têm a disposição marginal a pagar ou o custo médio como referência. Também, apresentam a tabela-resumo de modelos de cálculo possíveis para determinação das taxas, conforme a tabela 1 , a seguir.

Tabela 1 - Modelos de cálculo de taxas de drenagem

\begin{tabular}{|c|c|c|c|}
\hline $\begin{array}{c}\text { Determinaçáo de } \\
\text { Tarifas (Taxas) }\end{array}$ & Situaçáo & Vantagens & Problemas \\
\hline = Custo Marginal & $\begin{array}{l}\text { Mercado } \\
\text { Concorrencial }\end{array}$ & $\begin{array}{l}\text { - Maximizaçáo do bem- } \\
\text { estar social }\end{array}$ & $\begin{array}{l}\text { - Falta de interesse } \\
\text { ou impossibilidade } \\
\text { de definir a tarifa a } \\
\text { este nível: monopólio } \\
\text { natural. } \\
\text { - Maximizaçáo de } \\
\text { lucros por uma } \\
\text { empresa monopolista; } \\
\text { tarifas com funçóes } \\
\text { redistributivas etc. }\end{array}$ \\
\hline $\begin{array}{l}\text { = Benefício } \\
\text { Marginal }\end{array}$ & $\begin{array}{l}\text { Consumo não rival; } \\
\text { custo marginal nulo } \\
\text { e custo fixo positivo; } \\
\text { provisão } \\
\text { monopolística. }\end{array}$ & $\begin{array}{l}\text { - Aloca-se o bem de acordo } \\
\text { com o retorno econômico } \\
\text { para cada usuário. A } \\
\text { capacidade de pagamento } \\
\text { do consumidor é central } \\
\text { na metodologia. }\end{array}$ & $\begin{array}{l}\text { - Omitir os } \\
\text { verdadeiros } \\
\text { benefícios. Incentivo } \\
\text { ao carona. }\end{array}$ \\
\hline $\begin{array}{l}=\text { Ramsey Prices } \\
\text { A tarifa } \\
\text { aproxima-se do } \\
\text { custo marginal. }\end{array}$ & $\begin{array}{l}\text { Discriminação } \\
\text { de preços sobre } \\
\text { serviços ou sobre } \\
\text { consumidores. }\end{array}$ & $\begin{array}{l}\text { - Maximização do bem- } \\
\text { estar social como garantia } \\
\text { de receita que cubra os } \\
\text { custos. }\end{array}$ & $\begin{array}{l}\text { - As tarifas podem ser } \\
\text { indesejáveis do ponto } \\
\text { de vista distributivo. } \\
\text { - Requer informaçôes } \\
\text { detalhadas sobre } \\
\text { as demandas } \\
\text { individuais. }\end{array}$ \\
\hline = Custo Médio & $\begin{array}{l}\text { Necessidade de } \\
\text { cobrir custos (custos } \\
\text { marginais pequenos } \\
\text { e custos fixos muito } \\
\text { elevados). }\end{array}$ & $\begin{array}{l}\text { - Definição de tarifa não } \\
\text { abusiva que garanta a } \\
\text { viabilidade financeira da } \\
\text { firma. } \\
\text { - Relativa facilidade de } \\
\text { implementação. }\end{array}$ & $\begin{array}{l}\text { - Privilegia-se a } \\
\text { sustentabilidade } \\
\text { financeira. A } \\
\text { maximização do } \\
\text { bem-estar social não } \\
\text { é garantida. }\end{array}$ \\
\hline $\begin{array}{l}=\text { Custo Marginal } \\
\text { de Longo Prazo }\end{array}$ & $\begin{array}{l}\text { Eficaz, principalmente } \\
\text { quando, com o } \\
\text { aumento da escala } \\
\text { de produção, os } \\
\text { custos marginais } \\
\text { aumentam de forma } \\
\text { mais acelerada do que } \\
\text { os custos médios do } \\
\text { sistema. }\end{array}$ & $\begin{array}{l}\text { - Forma dinâmica } \\
\text { de tarifação, com a } \\
\text { incorporação de cenários } \\
\text { futuros de planejamento. } \\
\text { - Possibilidade de } \\
\text { maximização do bem-estar } \\
\text { social no longo prazo. }\end{array}$ & $\begin{array}{l}\text { - Dificuldades } \\
\text { para conhecer os } \\
\text { custos marginais } \\
\text { de longo prazo } \\
\text { (incertezas, mudanças } \\
\text { tecnológicas etc.). }\end{array}$ \\
\hline $\begin{array}{l}\text { = Custo Médio } \\
\text { de Longo Prazo }\end{array}$ & $\begin{array}{l}\text { Forma dinâmica } \\
\text { de tarifaçáo, com } \\
\text { a incorporação } \\
\text { de cenários de } \\
\text { planejamentos } \\
\text { futuros. }\end{array}$ & $\begin{array}{l}\text { - Forma dinâmica } \\
\text { de tarifação, com a } \\
\text { incorporação de cenários } \\
\text { futuros de planejamento. } \\
\text { - Possibilidade de garantir } \\
\text { recursos financeiros para } \\
\text { expansão do sistema no } \\
\text { longo prazo. }\end{array}$ & $\begin{array}{l}\text { - Dificuldades para } \\
\text { conhecer os custos } \\
\text { de longo prazo } \\
\text { (incertezas, mudanças } \\
\text { tecnológicas etc.). }\end{array}$ \\
\hline
\end{tabular}

Fonte: Adaptação própria a partir de Cançado, Nascimento e Cabral, 2005, p.22.

90 nível socialmente ótimo de poluição é o ponto onde a curva do custo de produção de uma unidade de escoamento cruza a curva do custo marginal de redução de uma unidade da água pluvial vertida. 
10 Em Porto Alegre, a diferença apurada com relação ao hidrograma natural, pré -ocupação urbana.
11 Disponivel em: <http:// www.rockymountnc.gov/publicworks/stormwater.html>. Acesso em: 10 fev.2011.
A lei brasileira exige que se quantifique o serviço disponibilizado para cada sujeito passivo da taxa, e por isso é necessário estimar o volume de água lançado (o que define a quantidade de poluente emitido ${ }^{10}$ ) individualmente no sistema pelo lote. Para este fim, precisa-se conhecer a área da bacia hidrográfica do modelo com sua parcela de áreas permeáveis e impermeáveis; a parcela da área de arruamento e logradouros públicos, como parques e praças, e de lotes urbanos; e o volume de água escoado pelo solo permeável e impermeável.

Enfatiza-se que a quantidade poluidora da água vertida em excesso é instável, uma vez que a área impermeável do lote pode ser alterada, sem maiores dificuldades, em algumas horas; basta que se realize algum procedimento que impeça a percolação da água no solo. Além disso, Baptista e Nascimento (2002, p.45) advertem que a mensuração do efetivo escoamento superficial é de difícil aplicação prática, pois exige o conhecimento da declividade do lote, além da correta aferição da área impermeabilizada; entretanto, o embasamento físico da cobrança torna-a mais facilmente perceptível para o consumidor.

De acordo com Tucci (2002, p.25), o coeficiente de escoamento superficial é de 0,15 para áreas permeáveis e de 0,95 para áreas impermeáveis. Logo, uma propriedade totalmente impermeabilizada gera 6,33 vezes mais volume de água do que uma propriedade não impermeabilizada, sobrecarregando o sistema nesta mesma proporção. Seguindo esta lógica, Gomes, Baptista e Nascimento (2008, p.95) consideram que a cobrança da taxa, de forma que o proprietário de um lote impermeabilizado arque com parte maior do custeio do serviço de drenagem urbana, é uma distribuição justa dos custos.

\section{FORMAS DE PRECIFICAÇÃO}

Há diferentes metodologias de cálculo para a estimativa de uma taxa de drenagem urbana. Muitas são inspiradas na taxa de drenagem implementada em Rocky Mount ${ }^{11}$, Carolina do Norte, EUA, que cobre os gastos de operação, manutenção e capital investido no sistema de drenagem do município, o que não é possível no Brasil. Selecionaram-se aquelas que podem se adequar ao uso no País (por não incorporarem ou possibilitarem a exclusão do custo de investimento e por serem individualizáveis), tais como:

a) Metodologia definida por Cançado, Nascimento e Cabral (2005, p.19):

Cme $=\mathrm{CT} /\left(\boldsymbol{\Sigma} \mathbf{v}_{\mathbf{j}}+\mathbf{v}_{\mathbf{v}}\right)$,

onde $\mathbf{C}$ me é o custo médio, $\mathbf{v}_{\mathbf{j}}$ é o volume lançado pelo imóvel $\mathbf{j} ; \boldsymbol{\Sigma} \mathbf{v}_{\mathbf{j}}$ é o volume produzido na área de lotes coberta pelo sistema; e $\mathbf{v}_{\mathbf{v}}$ é o volume produzido nas áreas públicas, como vias e praças, coberta pelo sistema.

ou

Cme $=$ CT / $\left(\boldsymbol{\Sigma} \mathbf{a}_{\mathrm{ij}}+\mathbf{a}_{\mathrm{iv}}\right)$,

onde $\mathbf{C}$ me é o custo médio, $\mathbf{a}_{\mathrm{ij}}$ é a área impermeável do imóvel $\mathbf{j} ; \boldsymbol{\Sigma} \mathbf{a}_{\mathrm{ij}}$ é a parcela do solo impermeabilizada pelos imóveis na área urbana coberta pelo sistema de drenagem; e $\mathbf{a}_{\mathrm{iv}}$ é a parcela do solo impermeabilizada pelas vias na área urbana coberta pelo sistema. 
E, assim, a taxa de drenagem pode ser definida como:

Taxa de drenagem $=\mathbf{p} \times \mathbf{a}_{\mathrm{ij}}$,

onde $\mathbf{p}$ = custo médio do sistema por metro quadrado de área impermeável ; e $\mathbf{a}_{\mathrm{ij}}$ é a área impermeável do imóvel j.

b) A metodologia sugerida por Tucci (2002, p.25) para o rateio do custo de operação e de manutenção dos sistemas de drenagem é:

$\mathrm{Cu}_{\mathrm{i}}=[100 * \mathrm{Ct}] /[\mathrm{Ab} *(15,8+0,84 * \mathrm{Ai})]$,

onde $\mathbf{C} \mathbf{u}_{\mathrm{i}}$ é o custo unitário das áreas impermeáveis, em $\mathrm{R} \$ / \mathrm{m}^{2}$; $\mathbf{C}$ t é o custo total para realizar a operação e manutenção do sistema, em $\mathrm{R} \$$ milhóes; $\mathbf{A b}$ é a área da bacia em $\mathrm{km}^{2}$; e Ai a parcela da bacia impermeável, em \%.

$\mathbf{T} \mathbf{x}=\left[\left(\mathbf{A} * \mathbf{C u}_{\mathbf{i}}\right) / 100\right] *\left(28,43+0,632 * \mathbf{i}_{1}\right)$,

onde $\mathbf{T} \mathbf{x}$ é a taxa anual a ser cobrada, pelo imóvel de área $\mathrm{A}\left(\mathrm{m}^{2}\right)$, em $\mathrm{R} \$$; $\mathbf{A}$ é a área do imóvel, em $\mathrm{m}^{2}$; $\mathbf{i}_{1}$ é o percentual de área impermeabilizado do lote; e $\mathbf{C u}_{\mathrm{i}}$ é obtido pela expressão acima.

c) A metodologia proposta por Gomes, Baptista e Nascimento (2008, p.97), que propóem uma taxa de manutenção do sistema, apresenta em sua composição uma parcela individual e outra comum a todos os lotes, proporcional às áreas permeáveis e impermeáveis destas parcelas:

$\mathrm{T}_{\text {man }}=\left(\mathrm{C}_{\text {manp }} / \mathrm{A}_{1}\right)^{*} \mathrm{~S}_{1}^{*}\left(1-\mathrm{T}_{1}\right)+\left(\mathrm{C}_{\text {mani }} / \mathrm{A}_{\mathrm{i}}\right)^{*} \mathrm{~S}_{1}^{*} \mathrm{~T}_{1}+\left(\mathrm{C}_{\text {manp }} / \mathrm{A}_{1}\right)^{*}\left(\mathrm{~A}_{\mathrm{SV}_{\mathrm{p}}} / \mathrm{A}_{\mathrm{b}}\right)^{*} \mathrm{~S}_{1}+\left(\mathrm{C}_{\text {mani }} / \mathrm{A}_{1}\right)^{*}\left(\mathrm{~A}_{\mathrm{SVl}} /\right.$ $\left.A_{b}\right) * S_{1}$,

onde $\mathbf{C}_{\text {manp }}$ é o custo de manutenção associado a áreas permeáveis, em R\$; $\mathbf{A}_{1}$ é a área total do lote, em $\mathrm{m}^{2} ; \mathbf{S}_{1}$ a área de cada lote, em $\mathrm{m}^{2} ; \mathbf{T}_{\mathbf{i}}$ o índice de impermeabilização dos lotes; $\mathbf{C}_{\text {mani }}$ o custo de manutenção associado a áreas impermeáveis, em $\mathrm{R} \$ ; \mathbf{A}_{\mathbf{s V}}$ são as áreas públicas (praças) e do sistema viário permeáveis, em $\mathrm{m}^{2} ; \mathbf{A}_{\mathbf{b}}$ é a área total da bacia, em $\mathrm{m}^{2}$; e $\mathbf{A}_{\mathrm{SVi}}$ são as áreas públicas (praças) e do sistema viário impermeáveis, em $\mathrm{m}^{2}$. E, o Custo de manutenção total é obtido (apud TUCCI, 2002):

$$
\mathrm{C}_{\text {man }}=\mathrm{C}_{\text {manp }}+\mathrm{C}_{\text {mani }}=\mathrm{C}_{\text {manp }}+6,33 \mathrm{C}_{\text {manp }} \text {. }
$$

Tucci (2003) admite que a dificuldade maior no processo de quantificaçáo da taxa está na estimativa da área impermeável de cada propriedade. Também, a complexidade do levantamento individualizado da área impermeável de cada lote, que é algo em constante mutaçáo, e o custo de um levantamento cadastral com esta especificidade praticamente inviabilizam a cobrança da taxa de drenagem urbana. Além disso, estudiosos da área de Recursos Hídricos divergem quanto ao rateio dos custos: pela Área Impermeável Total (AIT), Área Impermeável Efetiva (AIE) ou Alteração do Hidrograma Natural $\left(\mathrm{LID}^{12}\right)$.

12 Desenvolvimento Urbano de Baixo Impacto (Low Impact Development). 


\section{APLICAÇÃO DAS METODOLOGIAS: ESTUDO DE CASO}

O estudo de caso referente à aplicaçáo da taxa de drenagem deu-se sobre a área de abrangência da bacia de detenção do loteamento Ecoville Centro Comunitário, ilustrada na figura 1. Localiza-se na confluência da Avenida Francisco Silveira Bitencourt, no 1.155 com a Alameda Três de Outubro, na Bacia Arroio Santo Agostinho, na latitude sul de 29०59'51" e longitude oeste de 5107’25”. Em 2008 apurou-se uma população atendida de 590 habitantes residentes no loteamento (Carmona, 2008, p.45).

A permeabilidade dos espaços privados e públicos do loteamento Ecoville Centro Comunitário é obtida através do recorte da imagem do satélite de alta resoluçáo QUICKBIRD, de 2008, cedidas pela Prefeitura Municipal de Porto Alegre. Mediram-se as áreas permeáveis e impermeáveis das áreas privadas (quadras) e públicas (ruas e praças), através do método de classificação de imagens.

Figura 1 - Quadras e vias da bacia de detenção Ecoville Centro Comunitário

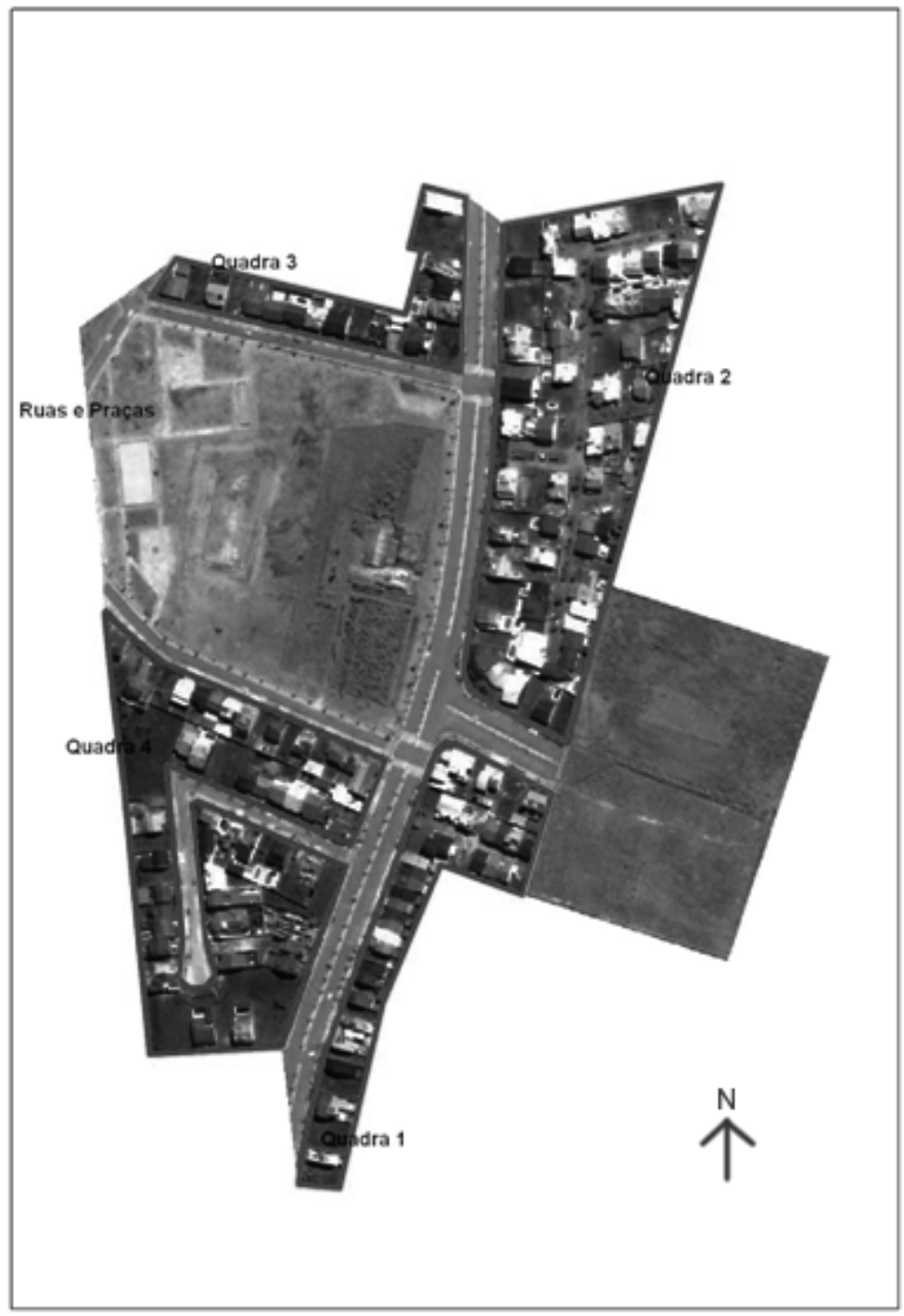

Fonte: Recorte da imagem do satélite QUICKBIRD, elaboração própria. 
Com a reclassificação das imagens espectrais claro-escuro da figura 2, obteve-se como resultado a tabela 2 , de onde se obtêm as áreas permeáveis e impermeáveis do loteamento.

Figura 2 - Imagem binária classificada para áreas permeáveis e impermeáveis

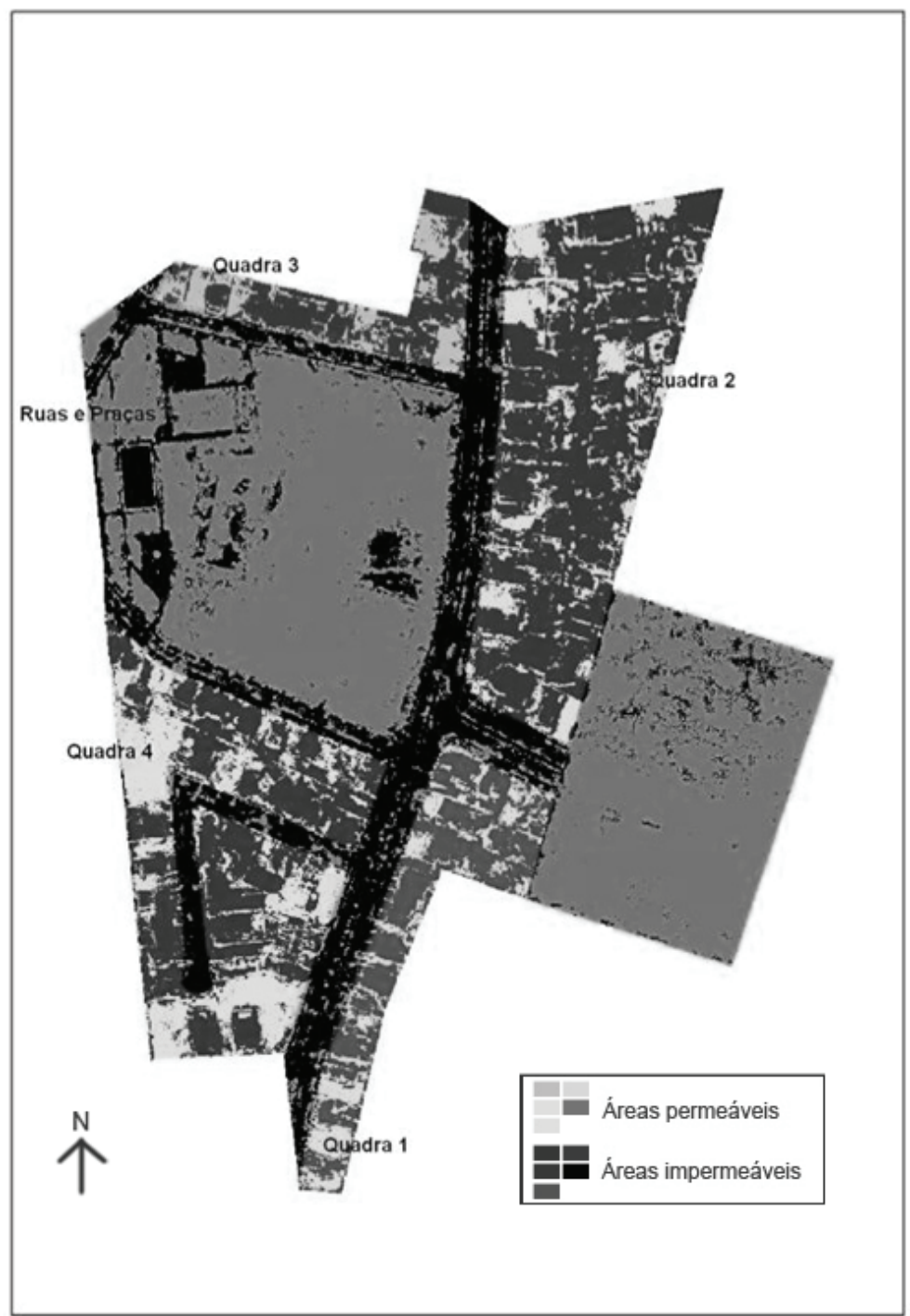

Fonte: Elaboração própria. 
Tabela 2 - Permeabilidade do solo da bacia do loteamento Ecoville em 2008

\begin{tabular}{|l|c|c|c|}
\hline Local/m & área Total & Área Impermeável & Área Permeável \\
\hline Quadra 1 & $9.462,96$ & $6.331,52$ & $3.131,44$ \\
\hline Quadra 2 & $26,068,92$ & $19.699,86$ & $6.369,06$ \\
\hline Quadra 3 & $6.583,51$ & $4.087,18$ & $2.496,33$ \\
\hline Quadra 4 & $21.184,09$ & $12.613,83$ & $8.570,26$ \\
\hline Ruas/Praças & $87.411,09$ & $27.746,75$ & $59.664,34$ \\
\hline Total $\mathbf{e m} \mathbf{~ m}^{\mathbf{2}}$ & $\mathbf{1 5 0 . 7 1 0 , 5 7}$ & $\mathbf{7 1 . 1 0 4 , 9 6}$ & $\mathbf{7 9 . 6 0 5 , 6 1}$ \\
\hline
\end{tabular}

Fonte: Elaboração própria.

Do resultado da análise espectral da área obtêm-se os seguintes dados:

Área da Bacia

Área total dos lotes

Área permeável total do sistema viário

Área impermeável total do sistema viário

Taxa de impermeabilização do loteamento

$$
\begin{aligned}
& \mathbf{A}_{b}=150.710,57 \mathrm{~m}^{2} ; \\
& \mathbf{A}_{1}=63.299,48 \mathrm{~m}^{2} ; \\
& \mathbf{A}_{\mathrm{SV}_{\mathbf{p}}}=59.664,34 \mathrm{~m}^{2} ; \\
& \mathbf{A}_{\mathrm{SVi}_{\mathrm{i}}}=27.746,75 \mathrm{~m}^{2} ; \\
& \mathbf{T}_{\mathbf{i}}=47,18 \% .
\end{aligned}
$$

Em face da inexistência de controle de custos no Departamento Municipal de Esgotos Pluviais do Município de Porto Alegre, RS, o custo de manutenção do reservatório foi obtido da relação de equivalência com o custo da obra. Estimado em 5\% dele, perfez em janeiro de 2008 um custo estimado em $\mathrm{R} \$$ 6.404,00 ao ano (Carmona, 2008, p.45). Para o mês de novembro de 2011 este custo, atualizado pelo CUB do projeto R8-N, é estimado em R \$ 8.452,42, para fins de cálculo.

Sabe-se, a partir dos ensinamentos de Tucci (2002, p.25), que uma propriedade totalmente impermeabilizada gera 6,33 vezes mais volume de água do que uma propriedade não impermeabilizada. Assim, tem-se que:

Se custo de manutenção: $C_{\text {man }}=C_{\text {manp }}+C_{\text {mani }}=C_{\text {manp }}+\mathbf{6 , 3 3} C_{\text {manp }}=R \$ 8.452,41$;

Logo,

custo de manutenção das áreas permeáveis:

$\mathrm{C}_{\text {manp }}=\mathrm{R} \$ 1.153,13$;

custo de manutenção das áreas impermeáveis

$\mathrm{C}_{\text {mani }}=\mathrm{R} \$ 7.299,29$.

Em vista da dificuldade de a Administração desenvolver formas de identificar a situação atual de ocupação de cada lote do município, que sofre mutação constante, e assim instituir uma cobrança da taxa sobre a situação real existente, sugere-se a adoção, como parâmetro máximo de ocupação do solo permeável, do definido pelo Plano Diretor de Desenvolvimento Urbano Ambiental de 1999, que absorveu a IN/SMAM no 22/2007 em sua alteração de 2011, definindo a área livre a ser preservada no lote. Ele será utilizado como variável na estimativa da cobrança da taxa de drenagem urbana para estimar a área impermeabilizada do lote neste estudo.

Este uso se justifica, de um lado, pela dificuldade e custo de um levantamento anual in loco para a correta atualização e obtenção desta informação no cadastro mu- 
nicipal, e, de outro lado, por se pressupor, para fins de planejamento urbano, que o proprietário tem como direito de uso da superfície do terreno até a ocupação máxima autorizada no Plano Diretor municipal. Por outro lado, ainda, há a possibilidade de o morador demonstrar a ocupação de seu lote e a utilização de técnicas compensatórias estruturais ${ }^{13}$ de vazão em seu lote.

A área livre (AL) mínima dos lotes, estimada de acordo com a IN/SMAM no 22/2007, deve ser de:

- Artigo 2o - 7\% para imóveis com área entre 151 e $300 \mathrm{~m}^{2}$;

- Artigos 3e e 6o - variável de acordo com no mínimo 70\% da área remanescente (AR) da taxa de ocupação (TO) ${ }^{14}$, para imóveis entre $301 \mathrm{~m}^{2}$ e $1500 \mathrm{~m}^{2}$; bem como para maiores de $1500 \mathrm{~m}^{2}$, com TO menor ou igual a $66,6 \%$.

$\begin{array}{llll}\circ & \text { TO } 90 \% & \text { AR } 10 \% & \text { AL 7“\%; } \\ \circ & \text { TO 75\% } & \text { AR 25\% } & \text { AL 17\%; } \\ \circ & \text { TO 66,6\% } & \text { AR 33,4\% } & \text { AL 23\%; } \\ \circ & \text { TO 50\% } & \text { AR 50\% } & \text { AL 35\%; } \\ \circ & \text { TO 20\% } & \text { AR } 80 \% & \text { AL 56\%. }\end{array}$

- Artigos 4o e 5o - Área livre de 20\%, para imóveis como áreas maiores a $1500 \mathrm{~m}$ e com TO maior $66,6 \%$.

A superfície do lote individual $\left(\mathbf{S}_{\mathbf{1}}\right)$ é definida $\mathrm{em}^{2}$.

Para fins de comparação de resultado, definiu-se a aplicação do cálculo das diferentes metodologias apresentadas no item anterior, para um terreno com $301 \mathbf{~ m}^{2}$ de superfície e taxa de ocupaçáo de $\mathbf{6 6 , 6 \%}$, localizado no loteamento Ecoville Centro Comunitário, em Porto Alegre. Para a obtenção da área do lote permeável de cada lote, de $70 \%$ da área não ocupada, é necessário deixar um mínimo de $23 \%$ de área livre permeável neste lote.

As taxas de drenagem urbanas foram calculadas segundo a:

a) Metodologia de Cançado, Nascimento e Cabral (2005, p.23), reproduzindo as equações (1), (2) e (3), adaptadas à nomenclatura definida acima. Tem-se que:

$\mathrm{C}_{\text {man }}=\mathrm{C}_{\text {man }} /\left(\mathrm{A}_{\mathrm{b}}{ }^{*} \mathrm{~T}_{\mathrm{i}}\right)$,

onde

$\mathrm{C}_{\text {man }}=8.452 /\left(150.710,57^{*} 0,4718\right)=\mathrm{R} \$ 0,1189 / \mathrm{m}^{2}$.

$\mathbf{T}_{\text {man }}=\mathbf{C}_{\text {man }}{ }^{*} \mathbf{a}_{\mathrm{ij}}$,

onde $\mathbf{a}_{\mathrm{ij}}$ é a área impermeável do imóvel j.

Considerando, para um imóvel de $301 \mathrm{~m}^{2}$ e taxa de ocupação de 66,6\%, a área livre permeável será de $23 \%{ }^{15}$, conforme a IN/SMAM no 22/07, assim, tem-se que $\mathrm{a}_{\mathrm{ij}}=231,77 \mathrm{~m}^{2}$. Logo,

$\mathbf{T}_{\operatorname{man}}=\mathrm{R} \$ 0,1189 / \mathrm{m}^{2 *} 231,77 \mathrm{~m}^{2}=\mathbf{R} \$ 27,55$ a.a. .
13 Cfe. Baptista, Nascimento e Barraud (2005, p.42), são "os procedimentos de favorecimento de retardamento dos escoamentos", como: pavimentos permeáveis, telhados verdes, poços de infiltração, valas e valetas etc.

14 No artigo no 112 , § 10, inc. VI, do PDDUA de Porto Alegre define-se taxa de ocupação (TO) como a "relação entre as projeções máximas de construção e as áreas de terreno sobre as quais acedem as construções".
15 Área livre permeável $=$ $301 \mathrm{~m}^{2} \times(100 \%-66,66 \%)$ $\times 70 \%=70,23 \mathrm{~m}^{2}$ 
b) Metodologia de Tucci (2002, p.25), reproduzindo as equaçóes (4) e (5), adaptadas à nomenclatura dos dados. Tem-se que:

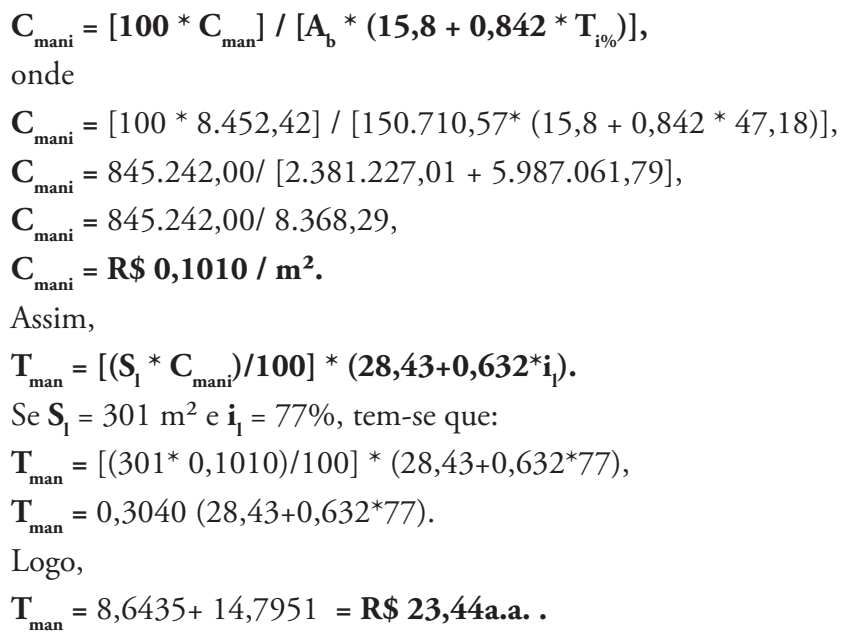

c) Metodologia de Gomes, Baptista e Nascimento (2008, p.97), utilizando-se como cenário de desenvolvimento a situação atual, reproduzindo a equação (6), com adaptação à nomenclatura adotada para os dados. Tem-se que:

$$
\begin{aligned}
& \mathrm{T}_{\text {man }}=\left(\mathrm{C}_{\text {manp }} / \mathrm{A}_{1}\right) * \mathrm{~S}_{1}^{*}\left(1-\mathrm{T}_{\mathrm{l}}\right)+\left(\mathrm{C}_{\text {mani }} / \mathrm{A}_{\mathrm{i}}\right) * \mathrm{~S}_{1} * \mathrm{~T}_{1}+\left(\mathrm{C}_{\text {manp }} / \mathrm{A}_{1}\right)^{*}\left(\mathrm{~A}_{\mathrm{SV}_{\mathrm{p}}} / \mathrm{A}_{\mathrm{b}}\right) * \mathrm{~S}_{1}+ \\
& \left(\mathrm{C}_{\text {mani }} / \mathrm{A}_{1}\right) *\left(\mathrm{~A}_{\mathrm{SVl}} / \mathrm{A}_{\mathrm{b}}\right) * \mathrm{~S}_{1},
\end{aligned}
$$

onde a taxa de drenagem apresenta ponderaçáo do custo da manutenção pelas áreas permeável e impermeável do lote e pelas áreas permeável e impermeável do loteamento.

$$
\begin{aligned}
& \mathbf{T}_{\operatorname{man}}=(1.153,13 / 63.299,48) * S_{1} *\left(1-i_{1}\right)+(7.299,29 / 63.299,48) * S_{1} * i_{1}+ \\
& (1.153,13 / 63.299,48) *(59.664,34 / 150,710,57) * S_{1}+ \\
& (7.299,29 / 63.299,48) *(27.746,75 / 150.710,57) * S_{1}, \\
& \mathbf{T}_{\operatorname{man}}=0,0182 * S_{1 *}\left(1-i_{1}\right)+0,1153 * S_{1} i_{1}+0,0182 * 0,3959 * S_{1}+0,1153 * 0,18411_{*} S_{1}, \\
& \mathbf{T}_{\operatorname{man}}=0,0182 * S_{1 *}\left(1-i_{1}\right)+0,1153 * S_{1} * i_{1}+0,0072 * S_{1}+0,0212 * S_{1} .
\end{aligned}
$$

Supondo que a Taxa de Ocupaçáo definida na lei municipal seja de 66,66\%, com área permeável de $23 \%$, tem-se que $\mathbf{i}_{1}=77 \%$, logo:

$$
\begin{aligned}
& \mathbf{T}_{\operatorname{man}}=0,0182 * S_{1 *}(1-0,77)+0,1153 * S_{1 *} 0,77+0,0072 * S_{1}+0,0212 * S_{1}, \\
& \mathbf{T}_{\text {man }}=\mathbf{0 , 0 0 4 2}{ }_{*} \mathbf{S}_{\mathbf{1}}+\mathbf{0 , 0 8 8 8} * \mathbf{S}_{\mathbf{1}}+\mathbf{0 , 0 0 7 2} \boldsymbol{S}_{\mathbf{1}}+\mathbf{0 , 0 2 1 2} \boldsymbol{S}_{\mathbf{1}} . \\
& \text { Para um lote de } 301 \mathrm{~m}^{2} \text { de superfície }\left(\mathbf{S}_{\mathbf{1}}\right) \text { tem-se que: }
\end{aligned}
$$$$
\mathrm{T}_{\operatorname{man}}=\mathrm{R} \$ 1,26+\mathrm{R} \$ 26,72+\mathrm{R} \$ 2,17+\mathrm{R} \$ 6,38=\mathrm{R} \$ 36,53 \text { a.a. . }
$$

E, para um lote-padrão de $301 \mathrm{~m}^{2}$, tudo o mais constante, variando apenas a taxa de impermeabilização do solo, conforme definido no PDDUA, para a taxa de ocupação e área livre do terreno, tem-se uma taxa anual, conforme apresentado na tabela 3: 
Tabela 3 - Variação da taxa de drenagem relacionando a área impermeável à taxa de ocupação legal

\begin{tabular}{c|c|c|cccc|c}
\hline $\begin{array}{c}\text { TO } \\
(\%)\end{array}$ & $\begin{array}{c}\mathrm{Ai} \\
\left(\mathrm{m}^{2}\right)\end{array}$ & $\mathrm{Ti}$ & $\begin{array}{c}\text { Lote Perm } \\
(\mathrm{R} \$)\end{array}$ & $\begin{array}{c}\text { Lote Imp. } \\
(\mathrm{R} \$)\end{array}$ & $\begin{array}{c}\text { Sist. Viár. Perm. } \\
(\mathrm{R} \$)\end{array}$ & $\begin{array}{c}\text { Sist. Viár. Perm. } \\
(\mathrm{R} \$)\end{array}$ & $\begin{array}{c}\text { Taxa Manuntençáo } \\
(\mathrm{R} \$ \text { a.a. })\end{array}$ \\
\hline 90 & 279,93 & 0,93 & 0,38 & 32,28 & 2,17 & 6,38 & 41,21 \\
75 & 249,83 & 0,83 & 0,93 & 28,81 & 2,17 & 6,38 & 38,29 \\
66,66 & 231,77 & 0,77 & 1,26 & 26,72 & 2,17 & 6,38 & 36,53 \\
50 & 195,65 & 0,65 & 1,92 & 22,56 & 2,17 & 6,38 & 33,02 \\
20 & 132,44 & 0,44 & 3,07 & 15,27 & 2,17 & 6,38 & 26,89 \\
\hline 24,52 & 142,01 & 0,47 & 2,89 & 16,37 & 2,17 & 6,38 & 27,81 \\
\hline
\end{tabular}

Fonte: Elaboração própria.

Para as áreas públicas, que são compostas pelas praças e ruas, tem-se um custo de manutenção de $\mathrm{R} \$ 8,55$. Entende-se que o custeio do serviço de drenagem das áreas públicas deva ser suportado pelo Poder Público através da tributação genérica dos impostos; logo, não pode ser cobrada através da taxa de drenagem ${ }^{16}$.

Verifica-se que, utilizando como cenário de desenvolvimento o definido no PDDUA e IN/SMAM no 22/2007, existe para os lotes individuais uma graduação de valor de acordo com sua área potencial máxima de impermeabilização, e para cada terreno uma parcela da taxa de drenagem urbana calculada em função de sua área permeável e outra de sua área impermeável. Já a taxa referente à parcela da área pública do loteamento, levantada através de fotointerpretação de imagem, se divide entre seu sistema viário permeável (praças) e impermeável (ruas) e tem um valor constante para todo o loteamento.

$\mathrm{Na}$ comparação entre as três metodologias calculadas de taxa de drenagem urbana, a custos de novembro de 2011, para um lote de $301 \mathrm{~m}^{2}$ obtêm-se os valores apresentados na tabela 4. Por exemplo, considerando a taxa de ocupação legal do loteamento, de $66,66 \%$, caberia ao proprietário do lote uma taxa de drenagem urbana anual de $\mathrm{R} \$ 27,55$ pela metodologia de Cançado e colaboradores (2005), de R \$23,44 pela metodologia de Tucci (2002) e de $\mathrm{R} \$ 36,53$ pela metodologia de Gomes e colaboradores (2008), que inclui a cobrança pela drenagem pluvial da área pública (tabela 3) e $\mathrm{R} \$ 27,98$ sem ela. Já um lote privado com o mesmo percentual de impermeabilização do loteamento em 2008, data das imagens, seria tributado pela taxa de drenagem em $\mathrm{R} \$ 16,88$ a.a. pela metodologia de Cançado e colaboradores (2005), em R \$ 17,71 a.a. pela metodologia de Tucci (2002) e em R \$ 19,27 a.a. pela metodologia de Gomes e colaboradores (2008), sem a cobrança da drenagem pluvial pela área pública.

Tabela 4 - Comparação do valor do valor da Taxa de Drenagem Urbana segundo as diferentes metodologias

\begin{tabular}{c|c|c|ccc|}
\hline $\begin{array}{c}\text { TO } \\
(\%)\end{array}$ & $\begin{array}{c}\text { Ai } \\
\left(\mathbf{m}^{2}\right)\end{array}$ & Ti & $\begin{array}{c}\text { Cançado et al. } \\
\text { (R\$ a.a.) }\end{array}$ & $\begin{array}{c}\text { Tucci } \\
(\mathbf{R} \text { a.a.) }\end{array}$ & $\begin{array}{c}\text { Gomes et al. } \\
\text { (R\$ a.a.) }\end{array}$ \\
\hline $\mathbf{9 0}$ & 279,93 & 0,93 & 33,28 & 26,51 & 32,66 \\
$\mathbf{7 5}$ & 249,83 & 0,83 & 29,70 & 24,58 & 29,74 \\
$\mathbf{6 6 , 6 6}$ & $\mathbf{2 3 1 , 7 7}$ & $\mathbf{0 , 7 7}$ & $\mathbf{2 7 , 5 5}$ & $\mathbf{2 3 , 4 4}$ & $\mathbf{2 7 , 9 8}$ \\
$\mathbf{5 0}$ & 195,65 & 0,65 & 23,26 & 21,13 & 24,48 \\
$\mathbf{2 0}$ & 132,44 & 0,44 & 15,74 & 17,10 & 18,34 \\
\hline $\mathbf{2 4 , 5 2}$ & 142,01 & 0,47 & 16,88 & 17,71 & 19,27 \\
\hline
\end{tabular}

Fonte: Elaboração própria.

16 Entendimento este ja aventado por Nascimento, Cançado e Cabral (2006, p.144). 
As diferenças encontradas como valor resultante da aferição das taxas de drenagem urbana calculadas decorrem da concepção do método proposto por cada autor dos diferentes modelos apresentados. Na equaçáo de Cançado e colaboradores (2005, p.23), a cobrança da taxa de drenagem é estipulada pelo custo médio do sistema por metro quadrado de área impermeável do loteamento. O custo médio é, então, multiplicado apenas pela área impermeável do lote individual. Na metodologia de Tucci (2002, p.25), o custo de manutenção é inicialmente aplicado à área impermeabilizada do loteamento e depois à área impermeabilizada do lote. Mas, para isso, aplica duas proposiçôes obtidas através de pesquisas: 1a) um loteamento tem $25 \%$ de sua área ocupada por áreas públicas e $75 \%$ ocupado por áreas privadas. As ruas são $15 \%$ da área do loteamento, sendo $100 \%$ impermeáveis, e as praças são $10 \%$ da área do loteamento, com $0 \%$ de áreas impermeáveis, ou seja, são totalmente permeáveis; $2^{\text {a) }}$ o escoamento das áreas impermeáveis é 0,95 e o escoamento das áreas permeáveis é 0,15. Gomes, Baptista e Nascimento (2008, p.97) também optaram por utilizar os coeficientes de escoamento superficial para o rateio dos custos de manutenção dos sistemas de drenagem urbana entre permeáveis e impermeáveis de acordo com a metodologia de Tucci (2002), embora chamem atenção ao fato de que esta relaçáo pode ser facilmente alterada pelos gestores desses sistemas. A metodologia seguida apresenta a cobrança pela área impermeável e também pela área permeável, combinada com as parcelas individual (lote privado) e total do loteamento (quadras, ruas e praças), excluída a cobrança pelo serviço de drenagem pluvial das áreas públicas. Ela melhor responde aos requisitos da especificidade e da divisibilidade requeridos pelos artigos 77 e 79 do Código Tributário Nacional (Lei Federal no 5.172/66), pois desvincula o cálculo da taxa de drenagem pelo índice de impermeabilização do loteamento (ou bacia), passando a considerá-los de forma direta.

Os resultados apuraram um valor monetário relativamente baixo para a cobrança da taxa anual de drenagem urbana. Mesmo que a estimativa do custo do serviço fosse duplicada (para 10\% do custo da bacia de detenção), ainda assim a oneraçáo fiscal dificilmente alteraria a conduta do contribuinte. Logo, o pequeno valor a ser pago pelo serviço estatal não teria o condão de alterar a conduta poluidora (impermeabilizante do solo urbano) por parte do possuidor do lote, que preferiria pagar a reduzir a vazão de escoamento produzida em sua propriedade.

Mas, mesmo diante da dificuldade de adesão voluntária ao intento de redução da poluição com o uso do instrumento econômico da tributação extrafiscal na cobrança da taxa de drenagem urbana, a regulação da cobrança do serviço de operação e manutençáo com o uso do critério de rateio pela capacidade máxima de ocupação e impermeabilizaçấo do lote, conforme definido no PDDUA de Porto Alegre, RS, estabelece um critério de justiça, pois cobra mais dos que detêm maior "uso potencial" de ocupação do terreno (que normalmente também tem preço mais elevado quanto maior sua taxa de ocupação).

\section{CONCLUSÕES}

Verificou-se a dificuldade de criação, por lei específica, de uma taxa de drenagem pluvial urbana no Brasil. No âmbito do Direito Tributário, os tributaristas divergem de opiniấo quanto à possibilidade ou não da criação da taxa de drenagem em razão da utilização de recursos ambientais de domínio público, em virtude de estar autorizada 
na Constituição Federal apenas para o exercício do poder de polícia ou para serviços públicos "específicos e divisíveis", conforme o inc. II de seu art. 145.

$\mathrm{Na}$ literatura específica, alguns autores defendem que a instituição da taxa de drenagem está respaldada nos art. 12 e 20 da Lei no 9.433, de 1997, e outros recomendam cautela na utilização para a aplicação sobre serviços que envolvam recursos ambientais de domínio público. O contra-argumento à tese de impossibilidade da cobrança sobre o serviço público em sentido amplo, de fruição obrigatória, está em que a questão implica saneamento básico e bem-estar público, em similitude com a taxa de coleta de lixo.

Supondo que o sistema tributário passe a incorporá-la, as dificuldades na cobrança da taxa de drenagem pluvial estão, principalmente, na estimativa da área impermeável (de cada lote) e na inexistência de um sistema de quantificação de custeio da manutenção e operação do sistema de drenagem das águas vertidas prestados pelo departamento responsável pela execução do serviço, com centros de custo, no mínimo, por bacia hidrográfica. A estimativa, tanto do custeio quanto da área impermeável do solo, necessita ter como foco cada uma das bacias hidrográficas do município, para que possam ser tomadas como área de planejamento e gestão do sistema de drenagem, pois as consequências dos impactos resultantes da densificação e ocupação do solo urbano ocorrem de forma distinta em cada uma delas.

Desta feita, sugeriu-se a estimativa da área impermeável da área maior através de técnicas de geoprocessamento de imagens, e a do lote através do uso do percentual de sua ocupação máxima, estipulado no PDDUA, que incorporou em seu texto a Instrução Normativa no 22/2007 da Secretaria do Meio Ambiente do Município de Porto Alegre, que estipula a área livre mínima a ser preservada como permeável no terreno a priori, a ser confirmada pelo proprietário do lote. Este regramento pode ser adotado no cálculo da taxa de drenagem, considerando-se, assim, a máxima impermeabilização permitida como parâmetro de cobrança.

Entre as diferentes metodologias para a precificaçáo da taxa de drenagem demonstradas no trabalho (Cançado et al., 2005; Tucci, 2002; Gomes e colaboradores, 2008), concluiu-se que a metodologia mais adequada é a mais recente, uma vez que ela pondera o custo de manutenção tanto pela área menor (do lote) quanto pela área maior (do loteamento ou da bacia) pela proporção de suas superfícies permeáveis e impermeáveis. Definiu-se que o custeio da manutenção pluvial nas áreas públicas (ruas e praças) deve ser feito através da receita de impostos. Da adaptaçáo desta metodologia ao PDDUA obteve-se, para a área de estudo do Ecoville Centro Comunitário, uma taxa de drenagem anual de $\mathrm{R} \$ 26,89$ para um lote de $301 \mathrm{~m}^{2}$ com $20 \%$ de taxa de ocupação e $56 \%$ de área livre e de $\mathrm{R} \$ 41,21$ para um lote de $301 \mathrm{~m}^{2}$ com $90 \%$ de taxa de ocupação e $7 \%$ de área livre, por exemplo. A comparação entre as três taxas de drenagem estudadas obteve como valores anuais, para um terreno com a mesma área e $66 \%$ de taxa de ocupação e $32 \%$ de área livre, para as metodologias de Cançado e colaboradores (2005), $R \$ 27,55$; para a de Tucci, $R \$ 23$,44; e para a de Gomes e colaboradores (2008), $\mathrm{R} \$ 27,98$.

Muito provavelmente, diante da opção de reduzir a vazáo de escoamento produzida em sua propriedade o possuidor do lote optaria por pagar o tributo. A pequena contribuição anual resultante para a manutençáo do serviço de drenagem no loteamento deve-se, em parte, ao baixo custo de manutenção da bacia de detenção aberta em grama (estimada na proporção de $5 \%$ do custo da obra) e pelos percentuais de $47,18 \%$ de áreas livres existentes e de 32\% de áreas livres propostas pelo PDDUA para a área do loteamento Ecoville Centro Comunitário em Porto Alegre, RS. 
17 PORTO ALEGRE. Decreto № 15.371 , de 17 de novembro de 2006. Regulamenta o controle da drenagem urbana.

180 critério de eficiência de Pareto pode ser assim enunciado: "Um estado da economia é eficiente no sentido de Pareto quando não há nenhuma possibilidade de se melhorar a posição de pelo menos um agente dessa economia sem que com isso a posição de outro agente seja piorada" (1998, p.569).

19 Conforme preconizado pela teoria de Baumol e Oates (1971) citados por Lagemann (2002, p.305).

Cristina Lengler é mestre em Planejamento Urbano e Regional pela Universidade Federal do Rio Grande do Sul (UFRGS); agente fiscal da Receita Municipal de Porto Alegre, Brasil. E-mail: Cristina. lengler@gmail.com.

Carlos André Bulhões Mendes é pós-doutor em Planejamento Ambiental pela University of California (USA); professor do Instituto de Pesquisas Hidráulicas da Universidade Federal do Rio Grande do Sul (UFRGS), Brasil. E-mail: mendes@iph.ufrgs.br.
De forma geral, fica saliente que o caráter extrafiscal da taxa de drenagem pluvial não se aplica ao Brasil, dada a vedação da inclusão do investimento e do custo de capital na cobrança do tributo. Mas, mesmo sem o condão de alterar a conduta impermeabilizante do solo urbano por parte do possuidor do lote, o que dificulta a adesão voluntária ao intento da redução da poluição, a taxa de drenagem proposta, além de prover recursos aos serviços, estabelece um critério de justiça, pois considera a capacidade máxima de ocupação e impermeabilização do lote, conforme definido no PDDUA de Porto Alegre, RS, e onera com um valor maior os que têm maior "uso potencial" de ocupação do terreno.

Assim, embora a condição natural pré-ocupação seja a base utilizada para o cálculo da adequação das vazóes dos lotes em Porto Alegre ${ }^{17}$, não é o que se defende como regra-geral. Deve-se alcançar um uso parcimonioso do recurso natural solo de forma a garantir o equilíbrio do sistema no interior de uma bacia hidrográfica. Estes limites devem ser apresentados dentro de um modo de produção social no qual o grau ótimo de Pareto $^{18}$ é alcançado com uma satisfatória relação de uso e conservação do solo impermeável a um preço que permita a urbanização de forma a conservar as características de vazão da água em níveis aceitáveis.

Neste sentido, a busca do ótimo de Pareto do desenvolvimento urbano-ambiental deve se encontrar entre o desenvolvimento urbano e o econômico e a proteção dos recursos naturais. Portanto, não objetiva "zero" poluição, mas o ponto onde a perda marginal de bem-estar devido à impermeabilização do solo seja igual ao custo limite de reparação. Assim, estabeleceu-se que o cenário ótimo é o oriundo da escolha de um padrão de qualidade do meio ambiente-preço ${ }^{19}$ para o uso dos lotes urbanos, pois é o regrado em leis e regulamentos municipais.

Cabe, entấo, indagar: Seriam as inundaçóes urbanas uma consequência da ocupação irregular (incluindo a falta de fiscalização do cumprimento das leis) ou de um inadequado parâmetro técnico de planejamento (que se confronta com interesses conflitantes e, também, denota falta de conhecimentos, entre os quais o de não introduzir o estudo da região da bacia hidrográfica como condicionante)? Ou, simplesmente, conhecem-se as necessidades técnicas da infraestrutura necessária ao desenvolvimento da cidade e faltam recursos públicos para prover e manter as obras públicas necessárias?

Caso seja este o maior entrave para a eliminaçáo do problema de alagamentos pontuais nas cidades, tem-se neste estudo um instrumento econômico para o financiamento dos serviços de drenagem urbana. Os investimentos para obras terão de ser supridos através de outras formas de tributação (impostos ou contribuição de melhoria).

A questão fundamental, para a qual não se procurou encontrar resposta objetiva neste trabalho, é a de como desenvolver uma coerente estrutura social e econômica capaz de realizar o equilíbrio entre a reprodução dos sistemas naturais e a reprodução e distribuição social. Se a conduta social é decorrente da valoração que o particular faz do uso do recurso natural, não se trata de um problema de "escolha", mas de uma "opção política" ligada à estratégia de desenvolvimento a ser adotada. 


\section{REFERÊNCIAS BIBLIOGRÁFICAS}

AMARAL, P. H. Direito Tributário Ambiental. São Paulo: Revista dos Tribunais, 2007. 240p. BAPTISTA, M. B.; NASCIMENTO, N. O. Aspectos institucionais e de financiamento dos sistemas de drenagem urbana. RBRH: Revista Brasileira de Recursos Hidricos, Porto Alegre, v.7, n.1, p.29-49, jan./mar. 2002.

; BARRAUD, S. Técnicas compensatórias em drenagem urbana.

Porto Alegre: ABRH, 2005. 266p.

BRASIL. Constituição da República Federativa do Brasil. 1988. Disponível em: <http://www. planalto.gov.br/ccivil_03/constituicao/constitui\%C3\%A7ao.htm>. Acesso em: 23 mar. 2006.

Lei Federal no 5.172 , de 25 de outubro de 1966. Dispóe sobre o Sistema

Tributário Nacional e institui normas gerais de direito tributário aplicáveis à União, Estados e Municípios. Diário Oficial da Uniāo, Brasília, DF, 31 out. 1966. Disponível em: <http://www. planalto.gov.br/ccivil_03/Leis/L5172.htm>. Acesso em: 23 mar. 2006.

. Lei Federal no 9.433, 8 de janeiro de 1977. Institui a Política Nacional de Recursos

Hídricos, cria o Sistema Nacional de Gerenciamento de Recursos Hídricos, regulamenta o inciso XIX do art. 21 da Constituiçáo Federal e altera o art. 1o da Lei no ${ }^{\circ} .001$, de 13 de março de 1990, que modificou a Lei no 7.990, de 28 de dezembro de 1989. Diário Oficial da União, Brasília, DF, 9 jan. 1997. Disponível em: <http://www.planalto.gov.br/ccivil_03/Leis /L9433. htm>. Acesso em: 19 set. 2010.

CANÇADO, V.; NASCIMENTO, N.O.; CABRAL, J. R. Cobrança pela drenagem urbana de águas pluviais: bases conceituais. RBRH: Revista Brasileira de Recursos Hidricos, Porto Alegre, v.2, n.1, p.5-21, 2005.

.; __ . Cobrança pela drenagem urbana de águas pluviais: bases conceituais e princípios microeconômicos. RBRH: Revista Brasileira de Recursos Hídricos, Porto Alegre, v.11, n.2, p.15-25, 2006.

CARMONA, M. V. C. Gestão da Drenagem Urbana em Porto Alegre, RS. 2008. 102 f. Monografia (Especialização em Gestão Integrada em Saneamento) - Programa de Modernização do Saneamento, Ministério das Cidades e Escola Internacional da Água para o Desenvolvimento (HYDROAID) - Faculdade de Tecnologia, Universidade de Brasília. Brasília, 2008.

FIORILlO, C. A. P.; FERREIRA, R.M. Direito Ambiental Tributário. 3a ed. São Paulo: Saraiva, 2010. 204p.

GOMES, C.A.B.M.; BAPTISTA, M. B.; NASCIMENTO, N.O. Financiamento da Drenagem Urbana: uma reflexão. RBRH: Revista Brasileira de Recursos Hidricos, Porto Alegre, v.13, n.3, p.93-104, jul./set. 2008.

LAGEMANN, E. Tributação Ecológica. Ensaios FEE, Porto Alegre, v.23, n.1, p.301-324, 2002. Disponível em: <http://revistas.fee.tche.br/index.php/ensaios/article/viewFile /2064/2446>. Acesso em: 31 maio 2012.

MANSFIELD, E. Microeconomia: teoria e aplicaçôes. Rio de Janeiro: Campus, 1978.

NASCIMENTO, N.O.; CANÇADO, V.; CABRAL, J. R. Estudo da cobrança pela drenagem urbana de águas pluviais por meio da simulação de uma taxa de drenagem. RBRH: Revista Brasileira de Recursos Hidricos, Porto Alegre, v.11, n.2, p.135-147, 2006.

OLIVEIRA, R. G. Economia do Meio Ambiente. In: PINHO, D. B.; VASCONCELLOS, M.A. S. (Org.). Manual de Economia. 3.ed. São Paulo: Saraiva, 1998. p.567-581.

PORTO ALEGRE. Lei Complementar no 434, de 1ํ de dezembro de 1999. Dispóe sobre o desenvolvimento urbano no Município de Porto Alegre, institui o Plano Diretor de 
Desenvolvimento Urbano Ambiental de Porto Alegre e dá outras providências. Diário Oficial de Porto Alegre, RS. Disponível em: <http://www.portoalegre.rs.gov.br/planeja/spm/ default. htm>. Acesso em: 3 mar. 2011.

Decreto no 15.371 , de 17 de novembro de 2006. Regulamenta o controle da drenagem urbana. Diário Oficial de Porto Alegre, RS, 24 nov. 2006. Disponível em: <http:// www2.portoalegre.rs.gov.br/cgi-bin/nph-brs?s1=000028692.DOCN. \&l=20\&u=/netahtml/ sirel/simples.html\&p=1\&r=1\&f=G\&d=atos\&SECT1=TEXT>. Acesso em: 3 mar. 2011.

SÃO PAULO. Tribunal de Justiça. Arguição de Inconstitucionalidade no 990102477401 SP, do Órgão Especial. Suscitante: 15ª Câmara de Direito Público do TJSP. Interessados: SEMASA - Serviço Municipal de Saneamento Ambiental de Santo André e Maria Assumpção Valente Giacaglia. Relator: Des. Renato Nalini. Diário de Justiça Eletrônico, Caderno Judicial, 2a Instância, São Paulo, v.III, ed. 776, 31 ago. 2010, p.730. Disponível em: <http://esaj.tjsp. jus. br/cjsg/getArquivo.do?cdAcordao =4666922\&vlCaptcha=zZSWX>. Acesso em: 19 fev. 2011. SANTO ANDRÉ. Prefeitura Municipal. Lei nº 7.606, de 23 de dezembro de 1997. Dispóe sobre a taxa de drenagem de águas pluviais. Diário Grande ABC, São Paulo, 25 dez. 1997.

SEBASTIÃO, S. M. Tributo Ambiental: extrafiscalidade e função promocional do Direito. 1.ed. 2006. 5.reimp. Curitiba: Juruá, 2010. 352p.

TORRES, H.T. Da relação entre competências constitucionais tributária e ambiental: os limites dos chamados "tributos ambientais". In: (Org.). Direito Tributário Ambiental. São Paulo: Malheiros, 2005. p.96-156.

TUCCI, C.E.M. Gerenciamento da drenagem urbana. RBRH: Revista Brasileira de Recursos Hidricos, Porto Alegre, v.7, n.1, p.5-27, 2002.

Inundações e drenagem urbana. In: .; BERTONI, Juan Carlos

(Org.). Inundaçóes Urbanas na América do Sul. Porto Alegre: Associação Brasileira de Recursos Hídricos, 2003. p.45-150.

ABSTRACT Prevent cities floods in the cities requires a cash flow to finance the urban pluvial drainage system. It discusses the partial recovery of public funds spent on local system operation and maintenance, through the creation of pluvial drainage rate, with the focus on the peculiarities of the Brazilian tax system. The results demonstrate that this is not an environmental tribute, because the small amount would not change the conduct of the plot owner. But it satisfies the requirements of availability, specificity and divisibility of the articles 77 and 79 of the Brazilian Tax Code. The criterion established to obtain the waterproofing percentage of the study area combines the classification of soil types (permeable/impermeable) and their uses (privatelpublic). The classification of spectral images was applied for establishing the permeable rate in larger areas, whereas the criteria defined by PDDUA were applied to quantify the percentage of permeable areas of small plots.

K E Y W O R D S Regulatory taxation; Municipal taxation; Immovable property taxes; Urban pluvial drainage. 